\title{
MOISTURE CHANGES IN LODGEPOLE PINE BEFORE AND AFTER ATTACK BY THE MOUNTAIN PINE BEETLE ${ }^{1}$
}

\author{
BY R. W. REID ${ }^{2}$
}

Rob Reid served in the R.C.A.F. from 1942 to 1945. He received a B.S.F. degree in 1950 and an M.A. degrce in 1953 from the University of British Columbia and a Ph.D. from Montana State College in 1960. Since 1950 he has been employed by the Forest Entomology and Pathology Branch, Department of Forestry, Calgary, Alberta.

\section{$A B S T R A C T$}

The moisture content of the outer sapwood of non-infested lodgepole pine is normally about 85 to 165 per cent of oven dry weight. In trees that have been infested by the mountain pine beetle for one year, the sapwood moisture content can be as low as 16 per cent. There is a steep moisture gradient from about 160 per cent in the outer sapwood to about 30 per cent in the heartwood. The moisture content in the centre is slightly higher than in the adjacent wood. In infested trees the sapwood moisture is greatly reduced within a year after the attack but moisture in the heartwood is not altered appreciably. Trees infested early in the season drop to a lower moisture content by fall than trees infested later in the season. In non-infested trees there is a diurnal and a seasonal moisture march; these do not occur in infested trees. The rapid moisture loss in the sapwood of infested trees is associated with blue-stain infection and successful establishment of bark-beetle broods

\section{INTRODUCTION}

There is a pronounced reduction in the moisture content of lodgepole pine (Pinus contorta Douglas var. latifolia Engelmann) following a successful attack by the mountain pine beetle (Dendroctonus monticolae Hopkins). The data on tree moisture presented herein were obtained from both non-infested and infested trees that were 80 to 90 years old and, varied in diameter from 8 to 12 inches (d.b.h.) Attention was paid to intra- and inter-tree variations, as well as to diurnal and seasonal changes. An attempt was made to relate moisture loss with the presence of blue stain in the infested tree. This moisture study was part of a broader investigation into the biology of the mountain pine beetle (Reid, 1961) which was carried out near Invermere, British Columbia, and Banff, Alberta, in the period 1955-1960.

\section{Methods of Moisture Determination}

The moisture content of the inner bark and the outer sapwood was obtained using sample blocks one-quarter inch thick and one and one-half inches square taken from the four cardinal positions on each sample tree. The blocks were immediately wrapped in aluminum foil and placed in waterproof

\footnotetext{
${ }^{7}$ Contribution No. 792, Forest Entomology and Pathology Branch, Department of Forestry, Ottawa, Canada. Based on a Ph.D. thesis submitted to the Faculty of Graduate Studies at Montana State College.

${ }^{2}$ Forest Entomology and Pathology Laboratory, Calgary, Alta.
} 
containers. In a high humidity chamber the outer bark was removed from the block and discarded. The inner bark and outer sapwood were separated, individually re-wrapped, and weighed. The samples were then oven-dried for 24 hours at $105^{\circ} \mathrm{C}$, and reweighed. The percentage moisture content was calculated on an oven dry weight basis (o.d.w.) by the standard method as follows:

$$
\text { Fresh weight - dry weight }
$$

$$
\text { Dry weight }
$$

The saturation weight method of determining moisture content (Chalk and Bigg, 1956) was found to be impractical for samples obtained from successfully infested trees. This was due to the presence of blue-staining organisms, which inhibited saturation.

The vertical distribution of moisture was determined in the outer sapwood of five non-infested trees. These trees were felled and samples taken from them at the base, at the 5-foot level, and at 10-foot intervals above this point to the 35-foot level. Discs cut from two infested and two non-infested trees were used to determine the horizontal distribution of moisture: A series of samples was taken at one-eighth inch intervals across each disc.

The diurnal moisture contents of the outer sapwood and the inner bark were measured of four non-infested trees. Samples one-quarter by threequarters by one-half inches were taken at four-hour intervals for this purpose. The seasonal moisture march was determined in a number of non-infested and infested trees. Ten non-infested trees were sampled on May 30, June 26, July 24, August 25, and September 9. Five additional trees were added at each date, except the last, to circumvent possible effects of earlier sampling on the original test trees. (An analysis of these data indicated that previous sampling did not affect the moisture content of the current sample). Infested trees were sampled in the same way but at different times depending on the availability of suitable trees.

\section{Results AND Discussion}

Moisture contents varied at different levels of the stem in the non-infested trees, from 100 to 170 per cent, but no consistent trends were apparent (Fig. 1). A steep moisture gradient was noted along the horizontal axis in non-infested trees, from 160 per cent in the outer sapwood to about 30 per cent in the heartwood. A slight increase in moisture occurred near the centre (Fig. 2). Within infested trees the moisture content of the heartwood was not appreciably reduced in the first year following beetle attack. There was however, a considerable drop in the moisture content of the outer sapwood, to about 18 per cent (Fig. 2).

Comparisons at four aspects on each of a number of non-infested trees showed wide differences but there was no consistent relationship with aspect. In contrast, in infested trees moisture contents and the differences between aspects were greatly reduced one year after beetle attack. There were also intertree differences but these differences were reduced one year after attack. (Table 1). 


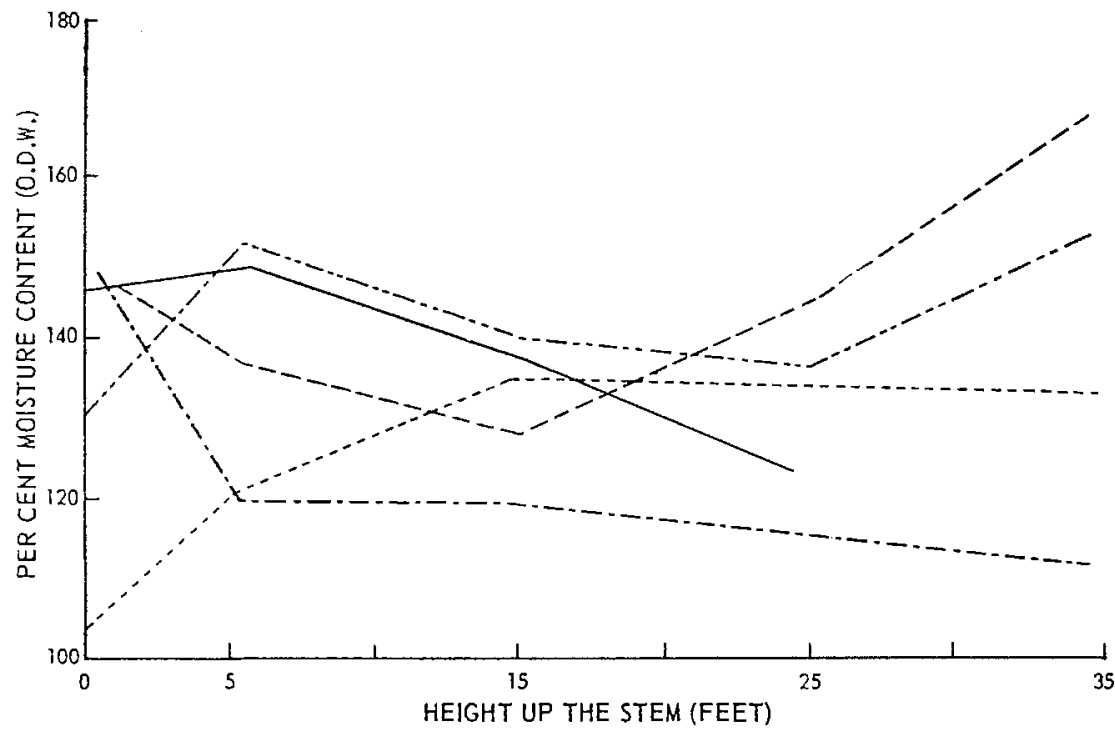

FIGURE 1. Vertical distribution of moisture in the outer sapwood of lodgepole pine.

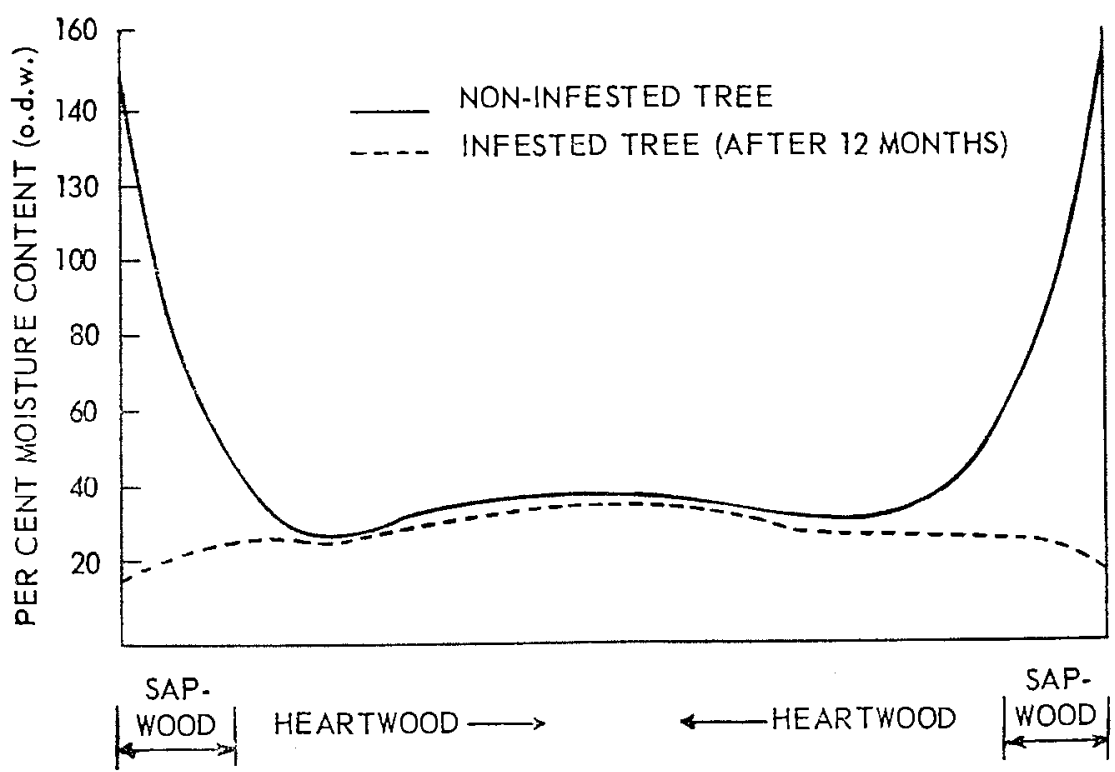

FIGURE 2. Horizontal distribution of moisture in a non-infested and infested lodgepole pine at the $31 / 2$-foot level. 
TABLE 1

Moisture Content in the Outer One-Quarter InCh of Non-Infested and Infested Lodgepole Pine on Four Aspects at the 31/2-FOOt LeVel

\begin{tabular}{rrrrrrrrrr}
\hline Tree & \multicolumn{3}{c}{} & \multicolumn{2}{c}{ Non-infested } & & Tree & \multicolumn{3}{c}{ One year following infestation } \\
\hline & N & \multicolumn{1}{c}{ E } & S & W & & N & E & S & W \\
\hline 1 & 143 & 131 & 116 & 105 & 6 & 18 & 17 & 18 & 18 \\
2 & 85 & 99 & 100 & 87 & 7 & 23 & 22 & 28 & 23 \\
3 & 95 & 104 & 117 & 135 & 8 & 18 & 20 & 23 & 27 \\
4 & 119 & 85 & 95 & 148 & 9 & 18 & 19 & 20 & 18 \\
5 & 118 & 107 & 108 & 124 & 10 & 19 & 19 & 17 & 27 \\
\hline
\end{tabular}

The moisture content in non-infested trees showed a gradual increase during the night and early morning followed by a gradual decrease during the afternoon (Fig. 3). Kramer (1956) found similar evidence of a diurnal change in southern pine saplings. There were also seasonal changes in the moisture content in non-infested trees (Fig. 4). Gibbs (1958) has reported seasonal trends with other coniferous species. Within successfully infested trees there was no diurnal or seasonal fluctuation in moisture content except minor ones due to changing atmospheric conditions.

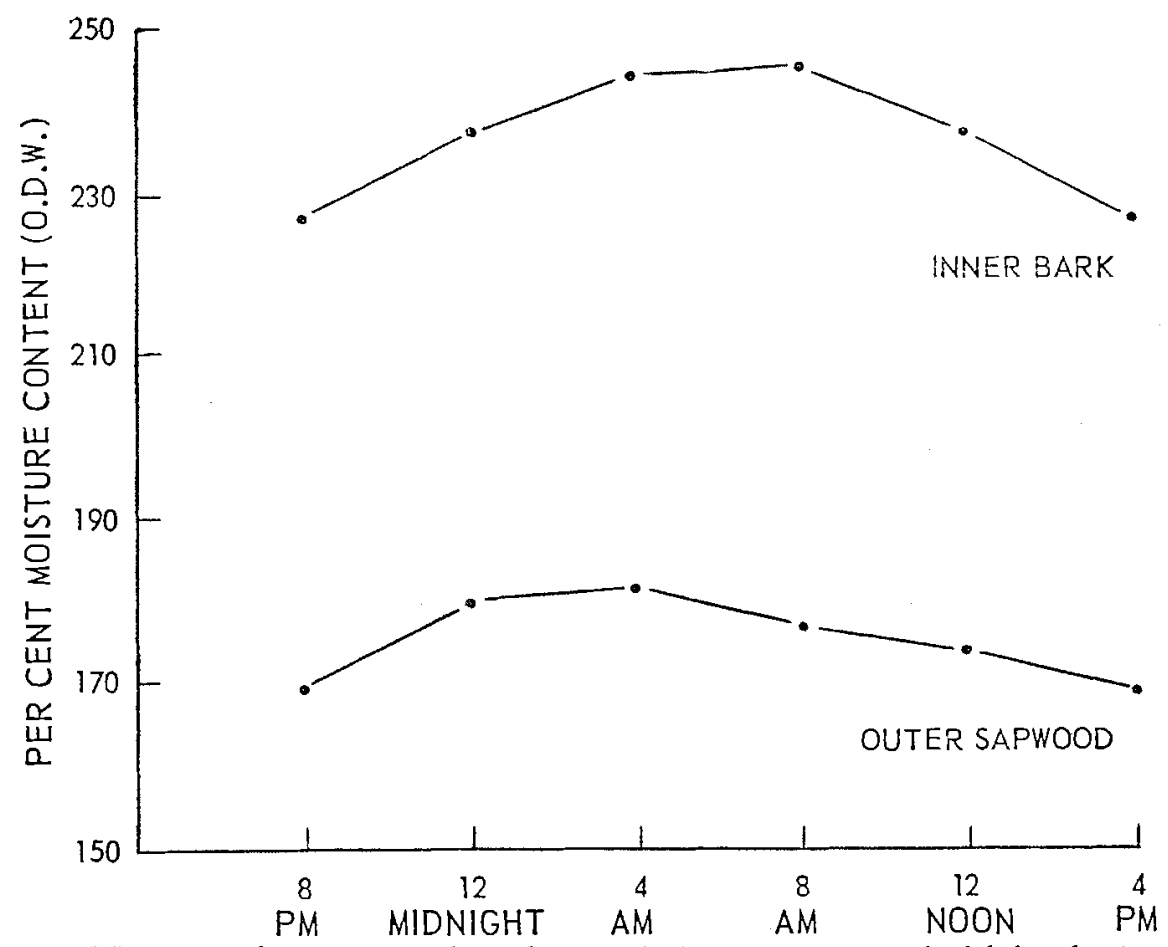

FIGURE 3. Diurnal moisture march in the inner bark and outer sapwood of lodgepole pine at the $31 / 2$-foot level. (Average of 4 trees). 


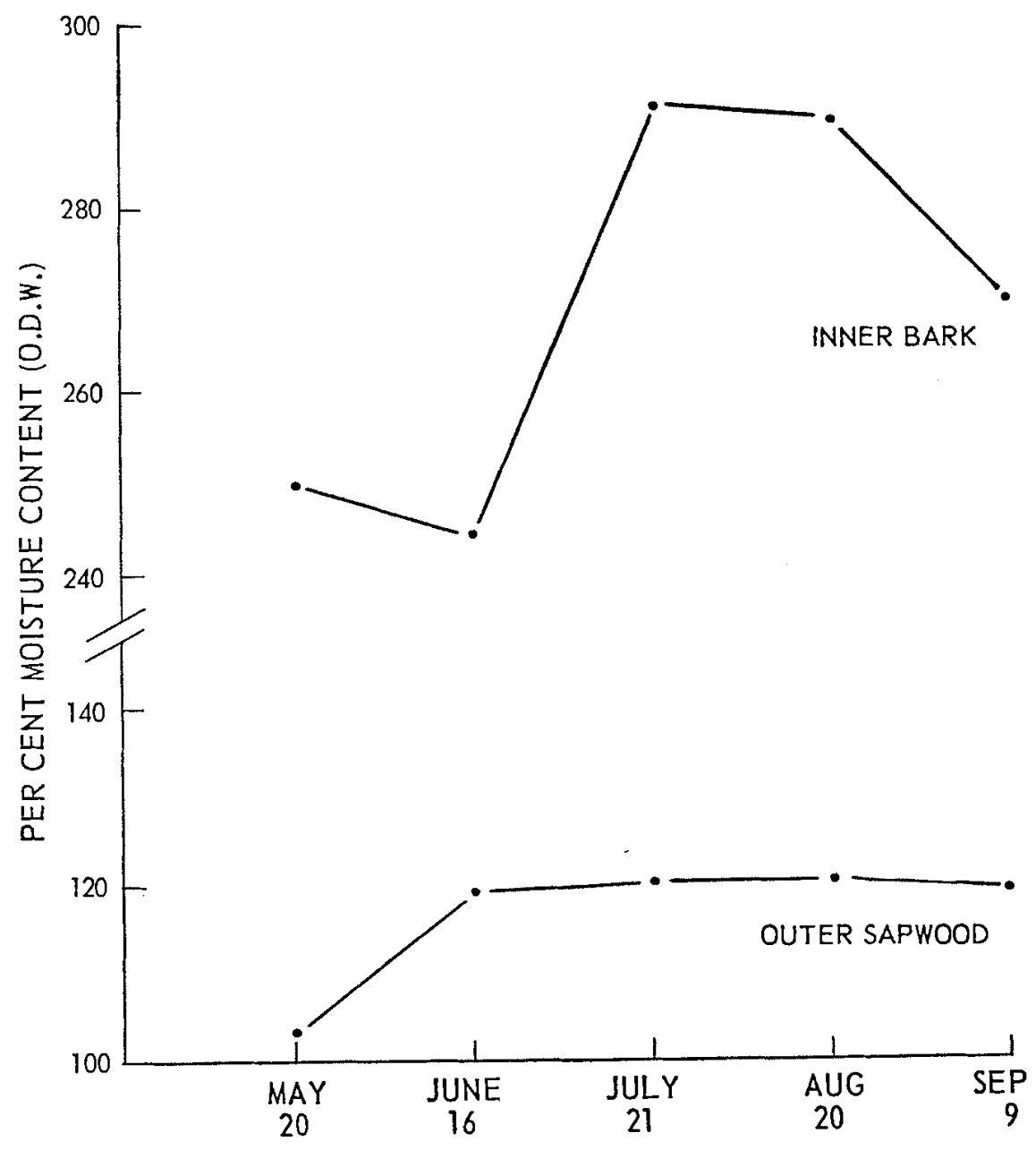

FIGURE 4. Seasonal moisture march in the inner sapwood and outer bark of lodgepole pine at the $3 \frac{1}{2}$-foot level.

The moisture content of the outer sapwood of infested trees was measured at intervals following beetle attack. Three groups of trees were studied: Group I, where galleries had been successfully established during the July flight and broods had developed; Group II, where galleries had been successfully established in the August flight and broods had developed; Group III, where gallery construction had been unsuccessful, i.e., short galleries had been constructed during both flights but broods had not developed.

Moisture conditions of trees in the three groups are illustrated in Figure 5. 


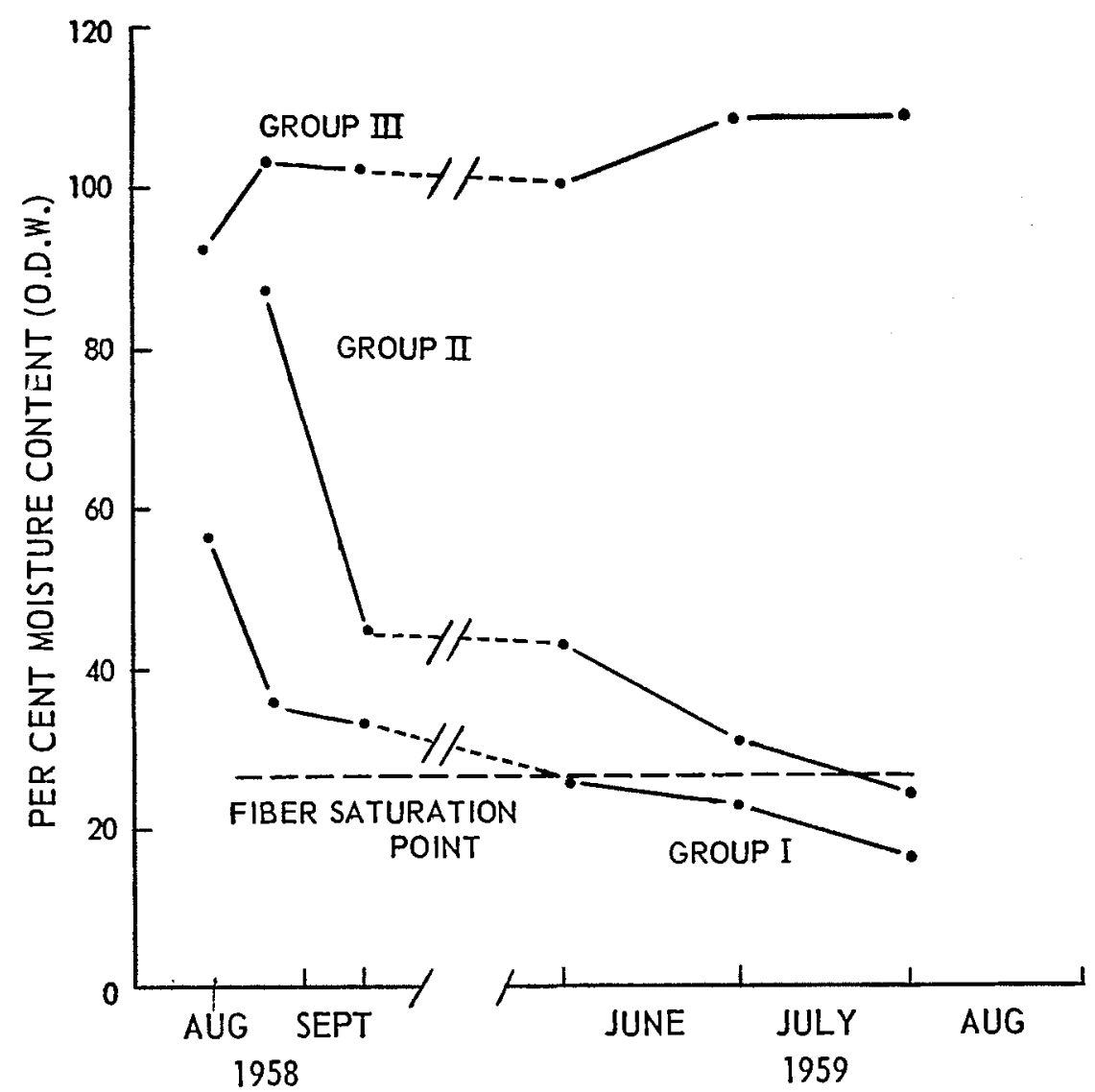

FIGURE 5. Seasonal moisture contents in the outer sapwood of successfully and unsuccessfully infested lodgepole pine at the $31 / 2$-foot level. (Group I were successfully infested in July, Group II in August, and Group III were unsuccessfully infested.)

Moisture measurements were not started until about three weeks following the initial attacks for trees of Groups I and III. In trees in Group II, measurements commenced within four days after the attack. The Group I trees had lost considerable moisture before measurements were started. Trees successfully attacked during the July flight (Group I) lost more moisture in the first season than trees successfully attacked during the August flight (Group II). The latter trees were about ten per cent higher on September 9th. By late May of the following year the moisture content of trees in Group I had fallen below fibre saturation point while the trees in Group II did not reach this level until mid-summer. Trees which did not succumb to the bark-beetle attacks retained a high moisture content; some of them had up to 50 attacks on the basal five feet of the stem but the broods were unable to become established. 
The rapid drying-out of bark-beetle infested trees has been related to blue-stain infection in the sapwood (Craighead, 1928; Nelson and Beal, 1929; Caird, 1935; Bramble and Holst, 1940). Robinson (1961) has recently shown several fungi of the blue-stain complex to be associated with the mountain pine beetle in lodgepole pine. Drying of the tree, blue-stain penetration, and development of bark-beetle broods are compared in Figure 6. The discs, as illustrated, were obtained in October, 1960, at the 1-foot level from trees infested during that same summer. At the time of felling there was no visible blue stain in two of the trees (Figs. 6a, b). In contrast, the sapwood in the third tree (Fig. 6 c) was heavily stained.

Most of the sapwood of one tree (Fig. 6a) appeared to be functional and the moisture content in the outer part of this sapwood was near 115 per cent. Where the broods were successfully established, the moisture content of the sapwood immediately below was drier, near 60 per cent, and was similar in appearance to the heartwood. Two weeks later the drier areas of the sapwood became completely stained but no staining occurred in the moist areas. A lesser amount of functional sapwood was present in another tree (Fig. 6b) in which more galleries were successful and broods had developed further. Moisture content was similar to that in the first tree and blue stain appeared in the drier portions of the sapwood after a period of two weeks. The moisture content of the third tree (Fig. 6c) was near 32 per cent and heavily blue-stained. All the broods in that tree had been successfully established and were in an advanced stage of development.

The low moisture content of the sapwood appears to be associated with the presence of blue stain in the sapwood and with the successful development of the bark-beetle broods (Fig. 7). It has not been established which, if any, of these conditions are causal and which are merely effect. Studies to this end are in progress.

\section{ACKNOWLEDGEMENTS}

Thanks are extended to H. C. Cerezky, Calgary, Forest Entomology and Pathology Laboratory, for assistance in the collection of samples, and to Pamela M. Morse, Statistical Research Service, Department of Agriculture, for statistical tests on the data. 


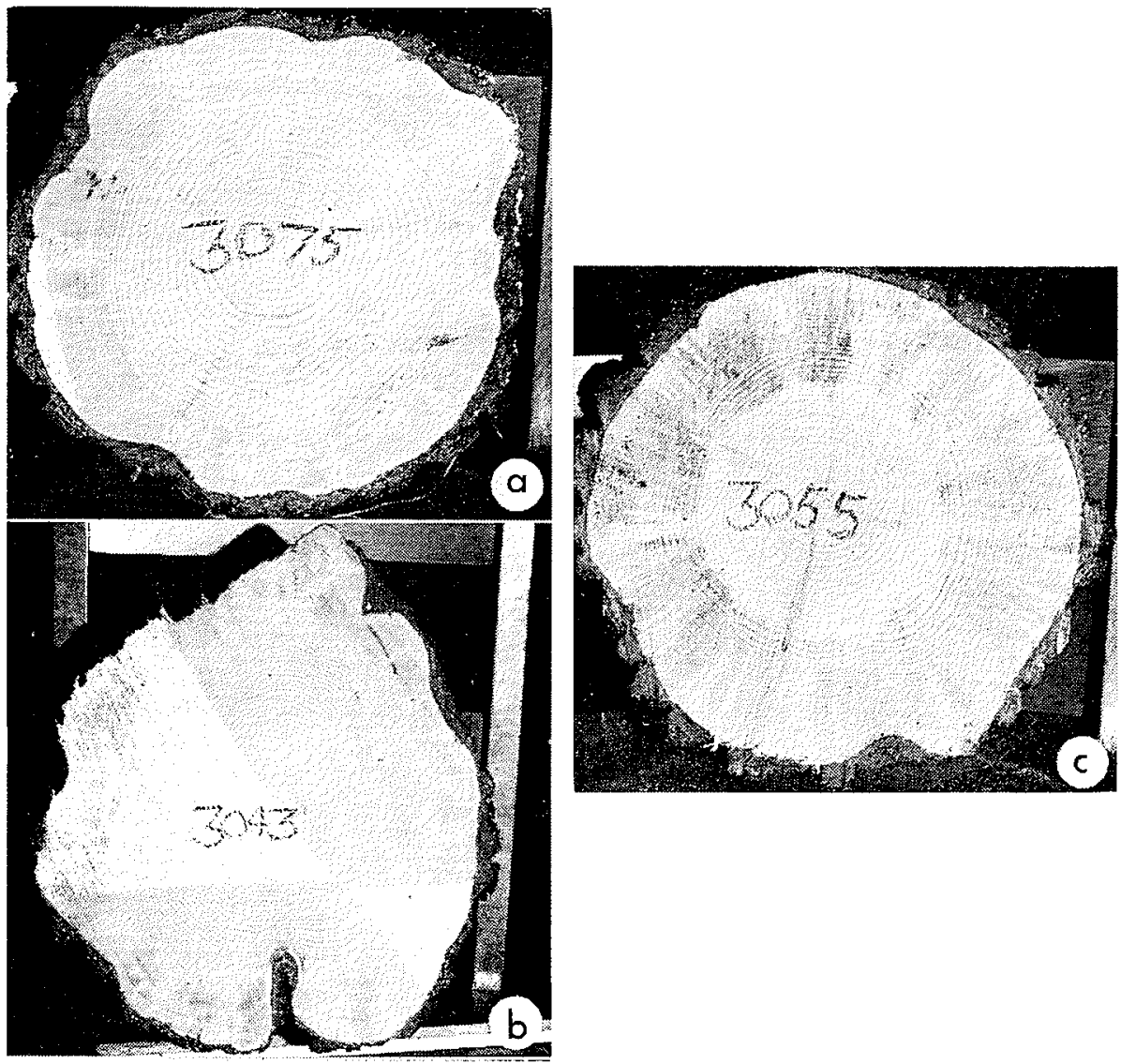

FIGURE 6. Cross sections, at the 1-foot level of three lodgepole pines, infested during the summer of 1960 and felled in October. (Dark areas in sapwood of "a" and "b" are moist and functional while light areas are drier and non-functional. No visible blue stain when felled. In "c" sapwood henvily bluc-stained and moisture content near fibre saturation point).

Figures for page 374 


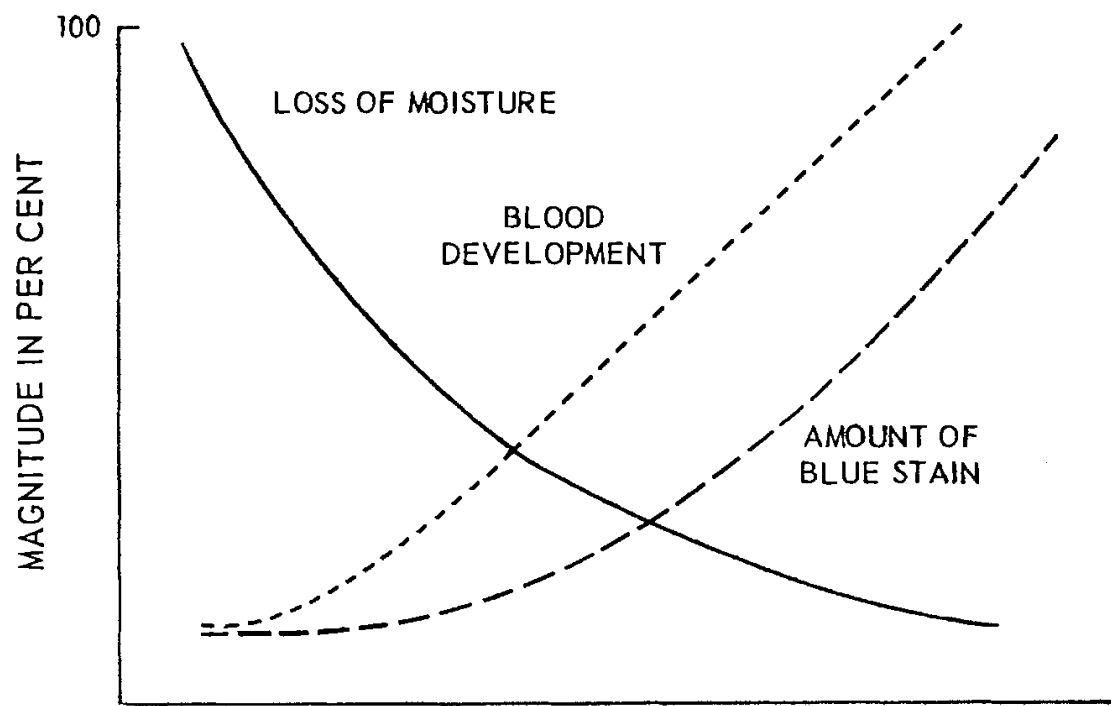

TIME

FIGURE 7. Diagrammatic illustration showing blue-stain penetration, drying out of the sapwood, and degree of brood development within infested lodgepole pine.

\section{REPERENCES}

BRAMBLE, W. C. and E. C. HOLST. 1940. Fungi associated with Dendroctonus frontalis in killing short leaf pines and the effects on conduction. Phytopathology, 30:881-899.

CAIRD, R. W. 1935. Physiology of pines infested with bark beetles. Bot. Gaz. 96:709-733. CHALK, L. and J. M. BIGG. 1956. The distribution of moisture in the stem in Sitka spruce and Douglas fir. Forestry, 29:5-21.

CRAIGHEAD, F. C. 1928. Interrelation of tree killing bark beetles and blue stain. Jour. Forestry 26:886-887.

GIBBS, R. D. 1958. Patterns in the seasonal water content of trees, - in Physiology of forest trees (symposium), ed. K. V. Thimann, Roland Press Co., New York.

KRAMER, P. J. 1956. Physical and physiological aspects of water absorption,-in Encyclopedia of Plant Physiology, Vol. III. Ed. W. Rubland, Springer-verlag. Berlin-Goltingen Heidelberg 1.

NELSON, R. M. and J. A. Beal. 1929. Experiments with blue stain fungi in southern pines. Phytopathology, 19:1101-1106.

REID, R. W. 1961. Studies on the biology of the mountain pine beetie. Can. Entomologist. (accepted for publication).

ROBINSON, R. C. 1961. Blue stain of bark-beetle-infested lodgepole pine. Can. Dept. For., For. Ent. and Path. Br. Bi-mon. Progr. Rept. 17(1). 